\title{
Identification and characterization of hydrothermally altered minerals using surface and space-based reflectance spectroscopy, in parts of south-eastern Rajasthan, India
}

\author{
S. L. Chattoraj ${ }^{1}$ - R. U. Sharma ${ }^{1} \cdot{\text { Chandan } \text { Kumar }^{2} \cdot \text { P. K. Champati ray }}^{1} \cdot$ Vivek Sengar $^{1}$
}

Received: 31 January 2019 / Accepted: 10 February 2020 / Published online: 2 March 2020

C) Springer Nature Switzerland AG 2020

\begin{abstract}
Imaging spectroscopy has evolved as one of the most significant advancements due to contiguous spectral coverage and higher spectral resolution which enable mineral identification and mineral exploration. Many phyllosilicate and carbonate minerals show specific spectral absorption feature in the wavelength range of visible-to-near-infra-red region of electromagnetic spectrum. These spectral features enable delineation of different mineral assemblages which in turn help in mineral prospecting using hyperspectral imaging spectra. The present study is focussed on evaluation and application of EO-1 Hyperion (hyperspectral) data as an Earth Observation tool for mineral detection and mapping in parts of Udaipur district in south-eastern Rajasthan. Hyperion reflectance imagery of this area was analysed using spectral angle mapper after pre-processing, atmospheric correction and geometric correction. Five endmembers, viz. dolomite, montmorillonite, chlorite, phlogopite and serpentine, were derived from both atmospherically corrected image and from rock samples in the laboratory using ASD field spectroradiometer covering spectral range of $0.4-2.5 \mu \mathrm{m}$. The reflectance spectra of endmembers derived from satellite image were initially compared with USGS mineral spectral library, and then after comparing with laboratory-based spectra with respect to absorption features, target minerals were identified which shows more than $70 \%$ match with the USGS and laboratory spectra. These minerals were also cross-checked with the reported litho-sequence of the area. Minerals derived from laboratory and image spectra are indicative of hydrothermally altered outer thermal aureole which is also corroborated by litho-structural association of the area.
\end{abstract}

Keywords Hyperion · Udaipur · SAM · Endmember · Mineral prospecting $\cdot$ Reflectance spectra

\section{Introduction}

In the field of mineral exploration, remote sensing has significant contribution in mapping of faults, fracture systems, host rocks and alteration/weathered zones indicative of mineral deposits [11, 16-18, 28-31, 48, 55]. High spectral resolution of hyperspectral sensors makes it an ideal complementary and confirming tool alongside traditional multi-spectral and field-based methods for mineral exploration [3]. Therefore, reflectance and emission spectroscopy in visible-to-near-infra-red and mid-infra-red have globally been used as an important tool for mineral characterization and exploration [8, 20, 22, 26, 32, 39, 44]. Data collected by imaging spectrometer using geometrically coherent spectral measurements facilitate quantitative and qualitative identification and mapping, thereby allowing a more detailed characterization of the spatial mineralogical heterogeneity using mixture analysis technique $[21,50-53]$.With the availability of more sophisticated and high-resolution spectrometers, the field of imaging spectroscopy from space, air or field has grown in terms of technical capability and application potential

S. L. Chattoraj, shovan.iitb@gmail.com | Indian Institute of Remote Sensing, 4-Kalidas Road, Dehradun, India. ${ }^{2}$ Department of Applied Mechanics and Hydraulics, National Institute of Technology Karnataka, Mangalore 575025, India. 
in geological mapping and mineral exploration $[12,13,19$, $27,33,35,36,43,45,54,56]$.

Although hyperspectral remote sensing techniques are operational since last two decades, the application of the same in Indian sub-continent has rather been limited mainly due to unavailability of space- or air-borne hyperspectral data. Works dedicated to mineral exploration taking cues from satellite-based data are still scanty and therefore hold promise for their application in mineral potential areas, so far unexplored or inadequately explored $[34,35,41,46]$. Such areas exist in the state of Rajasthan, which is one of the leading producers of metallic ores such as $\mathrm{Pb}-\mathrm{Zn}, \mathrm{Cu}$ and non-metallic ores like rock phosphate, gypsum, limestone, etc. Currently, 48 minerals are being mined out of 79 discovered minerals [10]. Therefore, considering the vast minerals potential of the state, the Government has recently proposed to increase its mining coverage from 0.4 to $1 \%$ by area [47]. Contemporary works around the globe also demand satellitebased studies to be incorporated to narrow down search for newer potential ore-rich zones. The present work, thus, aims at using space-based hyperspectral remote sensing data along with field-based spectroscopic data to address mineral exploration in Rajasthan.

The spectra derived from satellite image and field samples readily help to detect transitional element phases, viz. haematite, goethite and jarosite, which mainly show absorption dips because of electronic processes and alteration minerals containing hydroxyl ions and water like kaolinite, dickite, alunite and sericite that show absorption features due to vibrational characteristics $[5,6,24$, $37,38]$. Therefore, this fundamental property was used in both space-borne and ground-based spectral analysis to identify and classify the alteration zones based on abundance of diagnostic minerals. The study thus aims to identify and characterize the altered mineral phases associated with hydrothermal metallogenic process with the help of remote sensing data, especially in the VNIR wavelength range which may lead to zeroing in on potentially enriched, but relatively unexplored areas of or mineralization.

\section{Geological setting of the area}

The study area corresponds to vast north-eastern craton of India which preserves geological history from 3500 to $0.5 \mathrm{My}$ in a suit of metamorphosed rocks that have undergone polyphase deformation. The study area, albeit, represents a smaller part of it, situated mainly around Udaipur town ( $\mathrm{N} 24^{\circ} 37^{\prime}$ to $24^{\circ} 53^{\prime}$ and $\mathrm{E} 73^{\circ} 40^{\prime}$ to $73^{\circ} 48^{\prime}$ ). The basement represented by high-grade gneissic rocks of Archaean age is popularly known as Banded Gneissic
Complex, which consists of composite Mangalwar-Sandmata complex and meta-volcanics of Hindoli Group [15, 40] (Fig. 1).

The basement sequence is referred as Bhilwara Supergroup [14]. Towards eastern side of Udaipur town, sporadic occurrence of granite intrusion, viz. Untala Granite 2900 My [9], into the basement complex is observed. The Proterozoic supra-crustals, lying above Archaean basement, are represented by fold belts of Lower-to-Middle Proterozoic Aravalli Supergroup (aka. Aravalli Fold Belt, AFB) and Middle-to-Upper Proterozoic Delhi Supergroup (aka. Delhi Fold Belt, DFB). Two major stratigraphic divisions have been proposed for AFB, i.e. a shelf facies with basic lavas and coarse clastics at the base (Delwara and Debari Groups) exposed in the west and deep sea turbidite facies (Jharol Group) with Ultramafic intercalations in the east of the study area [25]. The contact between two facies, at places, is marked by a suture known as Rakhabdev Lineament [40]. Towards the eastern side of the study area, there occurs a prominent end-Archaean plutonic horizon known as Berach Granite in the vicinity of Chittorgarh. Towards further east, the Great Boundary Fault (GBF) occurs in close association with Berach Granite, delineated by an important zone of dislocation marked by a reverse fault which separates younger Vindhyan sedimentary sequence from older Pre-Vindhyan sequence [40]. Higher in the stratigraphy, the southern part of DBF is exposed towards the west of Udaipur, separated by a sheared and thrusted contact with AFB. The litho-sequence of the area, thus, is bounded between AFB-DFB thrusted contact in the west and GBF in the east. The recent alluvium mainly consists of weathered derivatives of gneiss, schist, phyllite, felsic and basic volcanics, dolomite and quartzite. The area is rich in several metallic and non-metallic mineral deposits, viz. lead, zinc, copper, rock phosphate, soapstone, limestone, dolomite, etc. [10], and there is an urgent need to explore further potential economic mineral deposits.

\section{Materials and methods}

The Earth Observation-1 (EO-1) Hyperion data of 19 January 2004 study (Scene Id: PO1H11480432004019110PZ) (Row/Pass: 143/43) was used for the present study. Additionally, a false colour composite subset ASTER image of Hyperion coverage area with sample location shows the study area (Fig. 2). The Hyperion sensor measures reflected solar radiation in 242 spectral bands covering the $400-2500 \mathrm{~nm}$ range of electromagnetic spectrum. However, only 169 bands were used for further processing as the bands were uncalibrated and noisy. The radiometric corrections were applied on the data to remove the noise such as line drops and bad columns. 


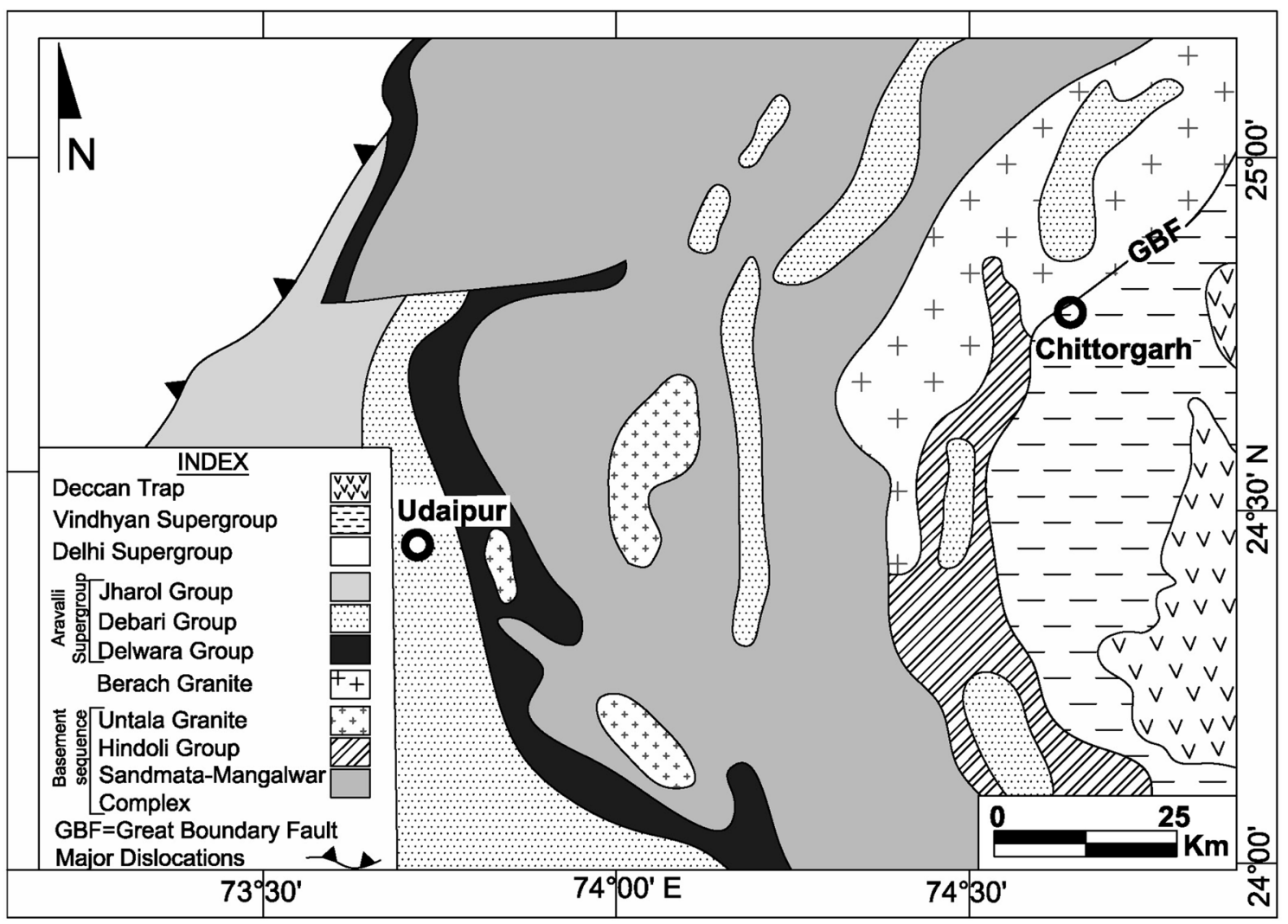

Fig. 1 Geological map of the area (modified after [40]

The bad columns were corrected by averaging the neighbouring columns. After the pre-processing, atmospheric correction of image was done using Fast Line-ofSight Analysis of Spectral Hypercubes (FLAASH) technique to convert radiance into apparent reflectance values as well as to suppress atmospheric effects with cloud percentage $>10 \%$ (Fig. 3, Table 1).

The MNF rotation was performed on atmospherically corrected image to determine the inherent dimensionality of image data. It also segregates the noise in the data and reduces the computational requirements for subsequent processing [2]. Pixel Purity Index (PPI) is used to find the most spectrally pure pixels in image. The Pixel Purity Index is computed by repeatedly projecting $\mathrm{n}$-dimensional scatterplots onto a random unit vector. The extreme pixels in each projection are recorded, and the total number of times each pixel is marked as extreme is noted. The final endmembers present in the area are selected from the pure pixels identified by PPI which are used as the training sets for classification (Fig. 4). The image was classified using spectral angle mapper (SAM) algorithm [23]. SAM expresses the similarity between the two spectra, which is derived by calculating the angle between the vectors representing the endmember spectra in the $\mathrm{n}$-dimensional space. This method is independent of illumination (i.e. topographic shading) and widely used for spectral matching.

Representative rock samples were collected during field survey and analysed in laboratory for derivation of spectral signature using Analytical System Device (ASD) FieldSpec 4 operating in wavelength range of $350-2500 \mathrm{~nm}$ at a sampling interval of $1.4 \mathrm{~nm}$ @350-1050 nm and 2 nm @1000-2500 nm. A contact probe was used to nullify the effect of atmosphere. These spectral profiles of rocks were compared with USGS (resampled to Hyperion bands) mineral spectral library in ENVI 5 to detect major or spectrally dominant minerals (Fig. 5). Similarly, selected endmembers derived from the image were compared with laboratory spectra followed by their validation with published lithological map.

$X R D$ investigation was employed to confirm the mineralogical outputs. XRD is one of the key methods to characterize phyllosilicates. The air-dried, powdered samples were scanned on a Rigaku Geigerflex X-ray diffractometer from $3^{\circ}$ to $60^{\circ} 2 \theta$ at $1^{\circ} 2 \theta /$ min scan speed, using nickel-filtered copper Ka radiation ( $40 \mathrm{kV}$ and $30 \mathrm{~mA}$ ). Subsequently, the samples were scanned after treating with ethylene glycol $\left(100^{\circ} \mathrm{C}\right.$ for $\left.1 \mathrm{~h}\right)$ and were finally scanned after heating at $490^{\circ} \mathrm{C}$ for $2 \mathrm{~h}$ under the same instrumental settings. The clay and mica phase 


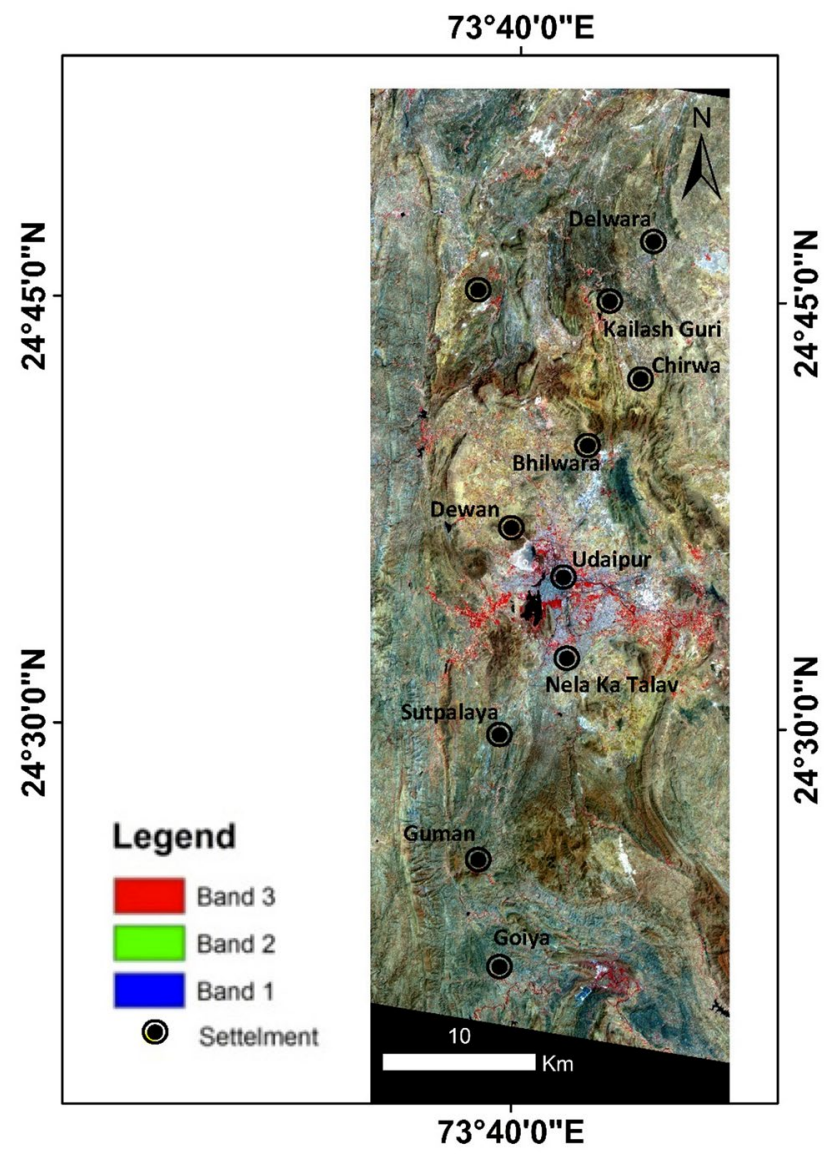

Fig. 2 Standard FCC of ASTER image (subset to area covered by Hyperion image) (RGB: 321) showing sample collection points

minerals were identified by their characteristic basal $\mathrm{X}$-ray diffraction maxima.

\section{Results}

The endmember minerals were derived after analysis of atmospherically corrected image using MNF and PPI. MNF resulted in selection of 14 bands of high eigenvalues out of 242 bands as they contained the maximum information. These 14 bands were used as an input for PPI which provided 5 endmembers. The endmembers were further classified using SAM algorithm. Subsequently, the endmembers were validated with field spectra which consist mainly of carbonate and silicate phases in the study area (Figs. 4, 5).

The extent of spectral match decreased significantly when the mutual similarity became less than 0.75 in spectral analyst operation of ENVI software. The pixels of the particular class classified using the SAM algorithm were matched with the field spectra, respectively. In addition to that, tie points generated on the image and the spectra of these points were also matched with the assigned class. Any deviation of this method will be considered under error of commission and omission. Confusion matrix, subsequently, was used to assess the accuracy of the final mineralogical classification of the area. The overall accuracy and Kappa coefficient of mineral map thus obtained from SAM are 0.71 and 0.54 , respectively. Endmember minerals were further analysed by X-ray diffraction studies of the collected samples from the key horizons (Fig. 6). The endmember of the classified image represents mineral paragenesis having phlogopite, montmorillonite, lizardite, dolomite and clinochlore which are indicative of hydrothermally altered suite. Spectral analysis revealed that the laboratory spectra have always remained smooth as compared to image spectra. This smoothness is attributed to uniform grain size, absence of atmosphere and exposure available at laboratory-scale samples. In the present study, except for lizardite and clinochlore, laboratory spectra of all other phases show closer match with USGS spectra compared to image spectra. As a whole, considering spectral response of both laboratory and image spectra, montmorillonite and phlogopite show maximum similarity with USGS spectra of the respective minerals. Holistically, all the image and laboratory-derived spectra of silicate phases bear signatures of $\mathrm{Mg}-\mathrm{OH}$ molecules at $2.3 \mu \mathrm{m}$. The paragenesis of the altered zone minerals reflects dominance of $\mathrm{Ca}$-, $\mathrm{Na}$ - and $\mathrm{Mg}$-rich phases, with very little or no K-bearing minerals. Considering the ubiquitous metallogeny of hydrothermal origin for different ores in this study area, the diagnostic minerals are interpreted to indicate an outer part of the thermal metasomatic zone.

\section{Discussions}

Dominant carbonate phase present in the field is mainly dolomite with negligible calcite and their ferroan counterparts. However, only dolomites have been revealed in the classified endmember map which shows less-pronounced absorption at $2.31 \mu \mathrm{m}$ compared to USGS spectra. This is attributed to impurity in carbonates in this region. Local mine tailings also indicate dominance of ubiquitous ferroan intercalation in dolomite. The relative flatness, specially in the visible region of laboratory spectra, indicates concentration of impinging energy on rather large pure euhedral dolomite grains as compared to image. The silicate phase present in the area is exemplified mainly by mica and clay minerals, viz. montmorillonite, phlogopite and chlorite. The image and laboratory spectral plots of montmorillonite show the typical absorption feature at 1.395 and $1.415 \mu \mathrm{m}$ caused by $(\mathrm{OH})$ overtone stretch and 1.95 to $2.208 \mu \mathrm{m}$ for the combination of $\mathrm{H}-\mathrm{O}-\mathrm{H}$ bend plus $(\mathrm{OH})$ stretch. Simultaneous occurrence of both these absorptions indicates a mineral having both 

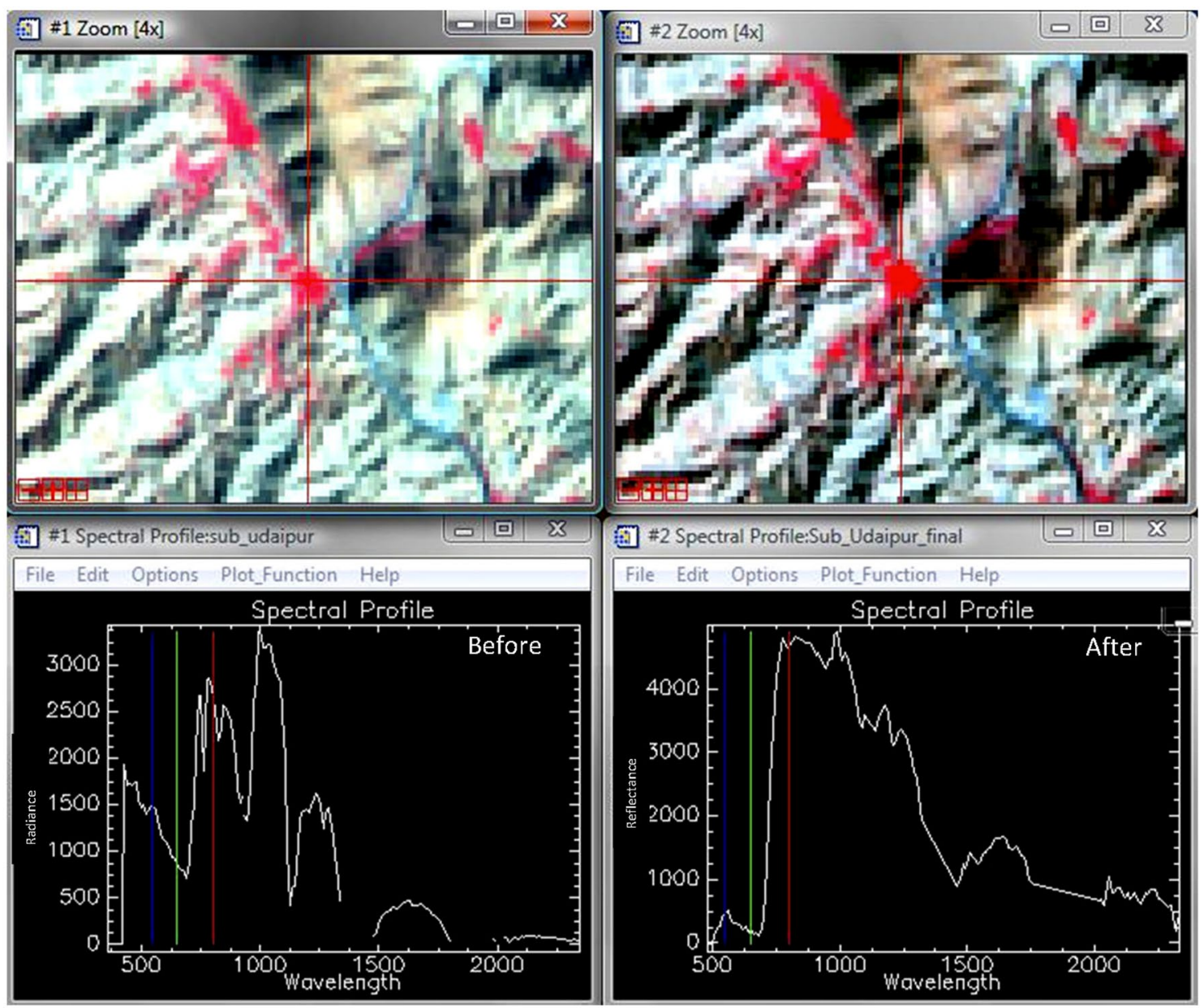

Fig. 3 Atmospheric correction of Hyperion image ( $X$-axis is rescaled)

Table 1 Parameters used for atmospheric corrections (FLAASH)

\begin{tabular}{ll}
\hline Sensor type & Hyperion \\
\hline Pixel size & 30 \\
Ground elevation & $0.6 \mathrm{~km}$ \\
Scene centre lat/long & $24.6^{\circ} \mathrm{N}, 73.7^{\circ} \mathrm{E}$ \\
Visibility & $40 \mathrm{~km}$ \\
Sensor altitude & $705 \mathrm{~km}$ \\
Flight date and flight time & $19 / 01 / 2004,5: 22: 17$ \\
Atmospheric model & Tropical \\
Aerosol model & Rural \\
Water vapour retrieval & $1135 \mathrm{~nm}$ \\
Wavelength calibration & Yes \\
Advanced parameters & \\
Output reflectance scale factor & 10,000 \\
MODTRAN resolution & $15 \mathrm{cms}^{-1}$ \\
MODTRAN multi-scattering model & Scaled DISORT 8 stream \\
CO $_{2}$ & $390 \mathrm{ppm}^{2}$ \\
\hline
\end{tabular}

$(\mathrm{OH})$ and $\mathrm{H}_{2} \mathrm{O}[1,7]$. The stronger absorption at 1.9 to $2 \mu \mathrm{m}$ also indicates predominance of water in the mineral over hydroxyl ion. However, it is most intriguing to note the conspicuous absorption due to the combination of metal (Al, $\mathrm{Mg}$ )-OH bend plus $\mathrm{OH}$ stretch, approximating 2.2 to $2.3 \mu \mathrm{m}$, which is evident both in image-derived and field spectra. Similarly, the diagnostic absorption feature of phlogopite at $2.3 \mu \mathrm{m}$ is caused by $\mathrm{Mg}-\mathrm{OH}$ bond and $\mathrm{OH}$ stretch. A small trough has also been recorded near $0.7 \mu \mathrm{m}$ in image spectra indicating probable replacement of $\mathrm{Mg} \mathrm{by} \mathrm{Fe}^{2+}$ in octahedral site. The occurrence of phlogopite pixels in the vicinity of meta-basics further geologically strengthens the potential ferric iron enrichment in phlogopite lattice. However, this small dip gets diminished and spectra become rather flat in the case of laboratory-scale samples. But in the NIR region, an almost perfect match between laboratory and image spectra was observed which varies from USGS spectra in terms of spectral slope in 2.2 to $2.4 \mu \mathrm{m}$ region. This results in a minor shift of the characteristic $2.3 \mu \mathrm{m}$ dip towards lower wavelength region in the case of laboratory sample. The image spectra of the least-abundant phyllosilicate, i.e. 


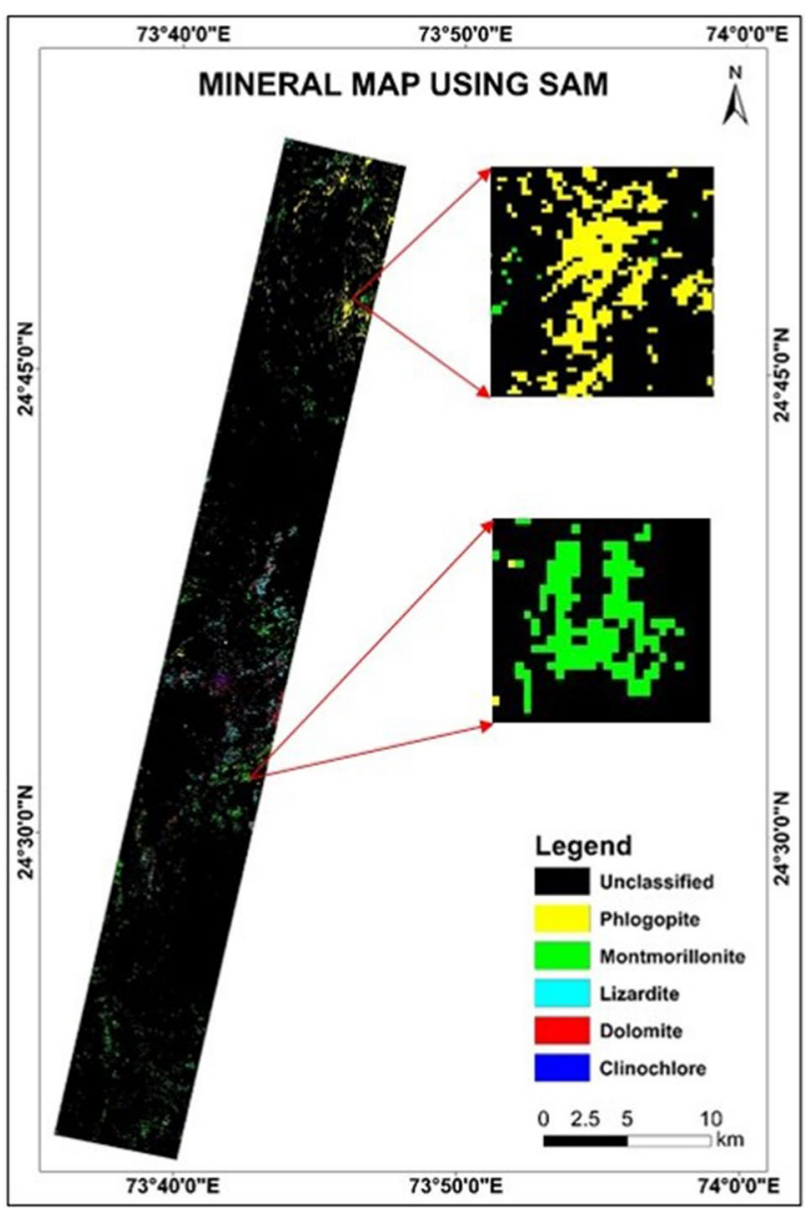

Fig. 4 SAM-classified mineral map of the area showing pure pixels of minerals

Chlorite (aka. Clinochlore), are noticed to show almost nearperfect match with USGS spectra except slight offset in dips occurring at 0.9 and $1.4 \mu \mathrm{m}$. Spectral similarity with phlogopite and characteristic dip at $2.3 \mu \mathrm{m}$ indicates that this variety of chlorite is also rich in $\mathrm{Mg}^{2+}$, thus interpreted as a clinochlore $[43,49]$. However, a less-pronounced absorption at $0.7 \mu \mathrm{m}$ cannot altogether rule out the presence of minor $\mathrm{Fe}^{2+}$. Therefore, Fe-bearing clinochlore is concluded to be more appropriate for this phase. The spectral plots of serpentine (aka. Lizardite) confirmed its presence owing to its diagnostic absorption at about $2.325 \mu \mathrm{m}$ caused by $\mathrm{Mg}-\mathrm{OH}$ molecules $[42,49]$. A similar feature is also observed in the
USGS spectra. As this phase is hydrous, it typically shows overtone absorptions due to the presence of $(\mathrm{OH})$ ions in the visible and near-infra-red regions. It has been revealed that dips at $1.4 \mu \mathrm{m}$ gets reduced in both image and laboratory spectra which are indicative of relatively $\left(\mathrm{OH}^{-}\right)$poor variant of serpentine group of minerals. But, it is very interesting to note the relatively stronger presence of $1.9 \mu \mathrm{m}$ absorption which corroborates the presence of water. This indicates the further progression of serpentine minerals in the serpentine-kaolinite solid solution series and development of neomorphic phase with little more dominance of $\mathrm{H}_{2} \mathrm{O}$ compared to serpentine. Brindely and Wann [4] reported the structural effect of transitional elements like $\mathrm{Ni}$ and $\mathrm{Fe}^{2+}$ in solid solution solutions related to serpentine group of minerals. In this study also, serpentines showing the presence of a broad absorption at $1 \mu \mathrm{m}$ due to crystal field effect is believed to be due to the presence of $\mathrm{Fe}^{2+}$ and $\mathrm{Ni}$ in the lattice. The diagnostic mineral assemblage, thus obtained, is indicative of distal portion of thermal metasomatic zone.

\section{Conclusions}

This study reveals how effectively high-resolution hyperspectral data can be utilized for detection and characterization of altered minerals in a potentially mineralized area. As for the main ore formation process, a hydrothermal origin can be concluded based on the rock types, structure and characteristic altered mineral paragenesis represented by species like phlogopite, montmorillonite, lizardite, dolomite and clinochlore. Integration of satellite image-based and ground-borne spectral analysis with geochemical validation confirmed the abundance of phases rich in $\mathrm{Ca}$, $\mathrm{Na}$ and $\mathrm{Mg}$ with a less K-bearing assemblage, which clearly is indicative of argillic or advanced argillic zone of hydrothermal alternation. This kind of mineralogical setup ideally follows a distal development of altered minerals away from the zone of intrusion. However, other complementary and field-based information is crucial to detect the particular zone or subzone of alteration. However, mainly employing satellite-based data and spectroscopy, an obvious lack of $\mathrm{K}$-metasomatism or sericitization in altered rock has been disclosed. Abundance of carbonate phases like dolomite also beseeches for the outer part of the thermal aureole of metasomatically altered zone system. 

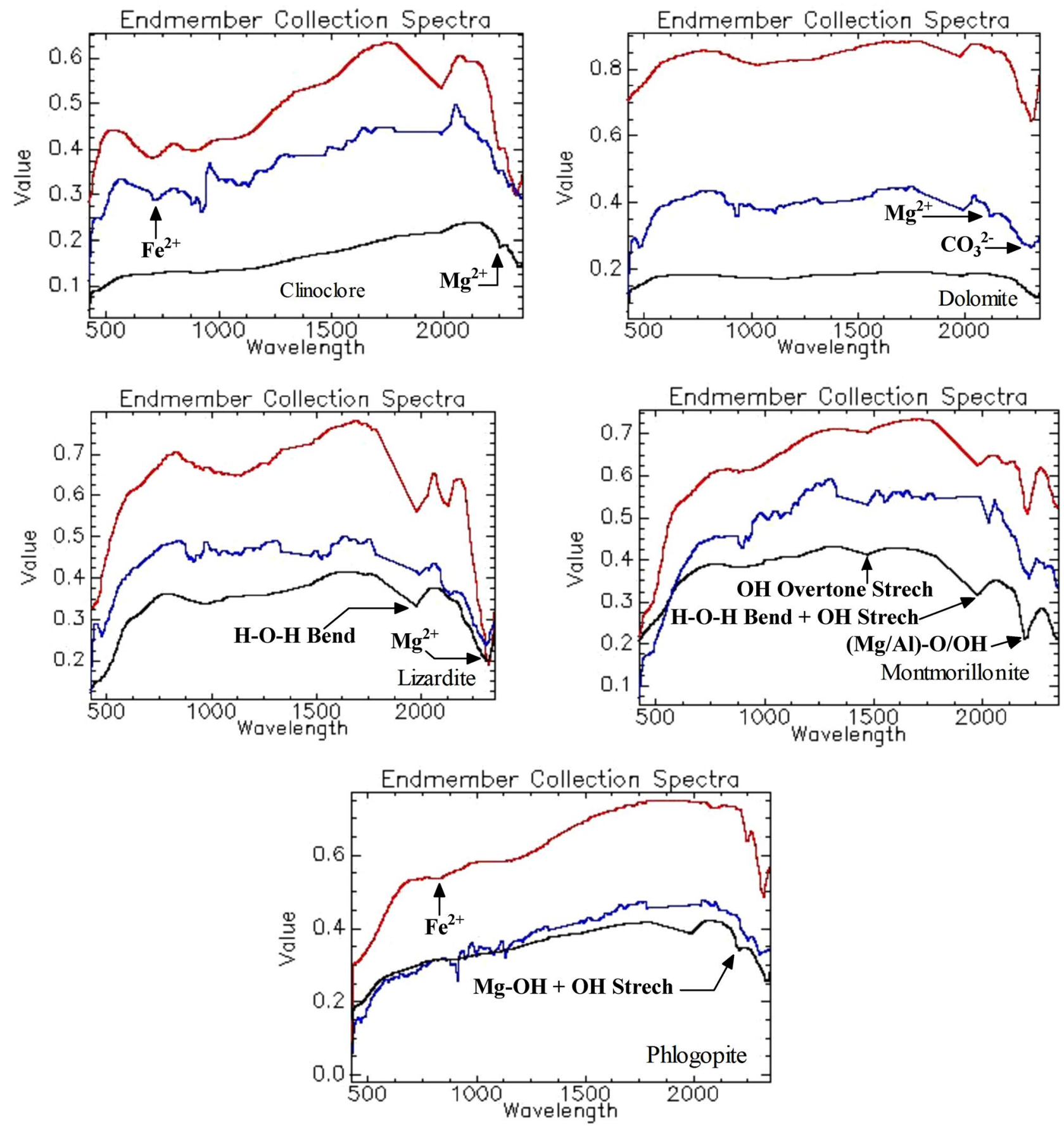

Fig. 5 Spectral responses of selected endmembers (line colours Red, Blue and Black show USGS library, image and field spectra, respectively) 


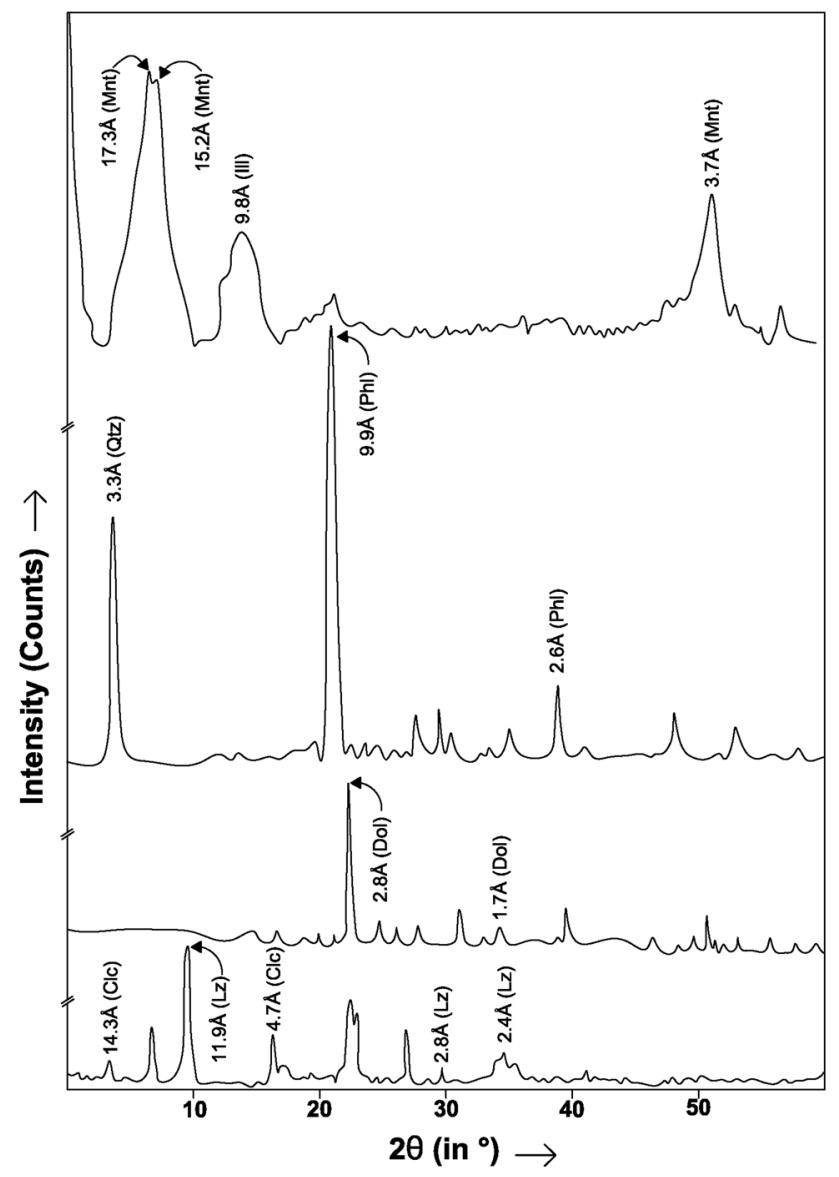

Fig. 6 X-ray diffractograms of five endmembers and associated minerals (abbreviations used: Clc: Clinochlore, Lz: Lizardite, Dol: Dolomite, Phl: Phlogopite, Mnt: Montmorillonite, Qtz: Quartz, IIl: Illite)

Acknowledgements The study was funded by ISRO EAOM project. The authors acknowledge infrastructural support provided by Indian Institute of Remote Sensing, Dehradun.

\section{Compliance with ethical standards}

Conflict of interest The author(s) declare that they have no competing interests.

\section{References}

1. Aines RD, Rossman GR (1984) Water in minerals? A peak in the infrared. J Geophys Res 89(B6):4059-4071

2. Boardman JW, Kruse FA (1994) Automated spectral analysis: a geological example using AVIRIS data, north Grapevine Mountains, Nevada. In: Proceedings of ERIM tenth thematic conference on geologic remote sensing, Environmental Research Institute of Michigan, Ann Arbor, pp 1407-1418

3. Borengasser M, Hungate WS, Watkins R (2007) Hyperspectral remote sensing: principles and applications. Taylor and Francis, Boca Raton, p 119

\section{SN Applied Sciences}

\footnotetext{
A SPRINGER NATURE journal
}

4. Brindley JW, Wann H (1975) Compositions, structures, and thermal behavior of nickel-containing minerals in the lizardite nepouite series. Am Miner 60:863-871

5. Burns R (1993) Mineralogical applications of crystal field theory, 2nd edn. Cambridge University Press, Cambridge, p 551

6. Clark RN, King TVV, Klejwa M, Swayze GA (1990) High spectral resolution spectroscopy of minerals. J Geophys Res 95(B8):12653-12680

7. Clark RN (1999) Spectroscopy of rocks and minerals, and principles of spectroscopy. In: Rencz AN (ed) Manual of remote sensing, volume 3: remote sensing for the earth sciences. Wiley, New York, pp 3-58

8. Cloutis EA (1996) Hyperspectral geological remote sensing: evaluation of analytical techniques. Int J Remote Sens 17:2215-2242

9. Chowdhury AK, Gopala K, Sastry CA (1984) Present status of the geochronology of the Precambrian rocks of Rajasthan. Tectonophysics 105(1-4):131-140

10. Geological Survey of India, Govt. of India (2011) Geology and mineral resources of Rajasthan, 3rd edn. Miscellaneous Publication, GSI, Kolkata, p 130

11. Goetz AFH, Vane G, Solomon JE, Rock BN (1985) Imaging spectrometry for earth remote sensing. Science 228:1147-1153

12. Goetz AFH, Chabrillat S, Lu Z (2001) Field reflectance spectrometry for detection of swelling clays at construction sites. Field Anal Chem Technol 5:143-155

13. Goetz FHA, Curtiss B, Shiley DA (2009) Rapid gangue mineral concentration measurement over conveyors by NIR reflectance spectroscopy. Miner Eng 22:490-499

14. Gupta SN, Arora YK, Mathur RK, Iqballuddin B, Sahai TN, Sharma SB (1981) Lithostratigraphic map of Aravalli range. Rec Geol Surv India 120:12-26

15. Heron AM (1953) Geology of Central Rajasthan. Memoirs of the Geological Survey of India 79:339

16. Hunt GR (1977) Spectral signatures of particulate minerals in the visible and near infrared. Geophysics 42(3):501-513

17. Hunt GR, Salisbury JW (1970) Visible and near-infrared spectra of minerals and rocks. Vol. 1: silicate minerals. Mod Geol $1: 283-300$

18. Hunt GR (1982) Spectroscopic properties of rocks and minerals. In: Carmichael RS (ed) Handbook of physical properties of rocks, vol 1. CRC Press, Boca Raton

19. Kodikara RL, Champati ray PK, Chauhan P, Chatterjee RS (2016) Spectral mapping of morphological features on the moon with MGM and SAM. Int J Appl Earth Obs Geoinf 44:31-41

20. Kruse FA (1996) Identification and mapping of minerals in drill core using hyperspectral image analysis of infrared reflectance spectra. Int J Remote Sens 17(9):1623-1632

21. Kruse FA, Boardman JW, Huntington JF (2003) Evaluation and validation of EO-1 hyperion for mineral mapping. IEEE Trans Geosci Remote Sens 41(6):1388-1400

22. Kruse FA (2012) Mapping surface mineralogy using imaging spectrometry. Geomorphology 137:41-56

23. Kruse FA, Lefkoff AB, Boardman JB, Heidebrecht KB, Shapiro AT, Barloon PJ, Goetz AFH (1993) The spectral image processing system (SIPS) - interactive visualization and analysis of imaging spectrometer data. Remote Sens Environ 44:145-163

24. Mitra S (1996) Fundamentals of optical, spectroscopic and X-ray mineralogy. New Age International Publishers, New Delhi

25. Naha K, Mohanty S (1988) Response of basement and cover rocks to multiple deformations: a study from the Precambrian of Rajasthan, western India. Precambr Res 42:77-96

26. Noori L, Pour BA, Askari G, Taghipour N, Pradhan B, Lee C-W, Honarmand M (2019) Comparison of different algorithms to map hydrothermal alteration zones using ASTER remote sensing data for polymetallic vein-type ore exploration: 
Toroud-Chahshirin Magmatic Belt (TCMB), North Iran. Remote Sens 11(5):495. https://doi.org/10.3390/rs11050495

27. Pour AB, Hashim M (2012) The application of ASTER remote sensing data to porphyry copper and epithermal gold deposits. Ore Geol Rev 44:1-9

28. Pour AB, Hashim M, Hong JK, Park Y (2019) Lithological and alteration mineral mapping in poorly exposed lithologies using Landsat-8 and ASTER satellite data: north-eastern Graham Land, Antarctic Peninsula. Ore Geol Rev 108:112-133

29. Pour AB, Park Y, Crispini L, Läufer A, Kuk Hong J, Park T-YS, Zoheir B, Pradhan B, Muslim AM, Hossain MS, Rahmani O (2019) Mapping listvenite occurrences in the damage zones of northern Victoria Land, Antarctica using ASTER satellite remote sensing data. Remote Sens 11:1408. https://doi.org/10.3390/rs11121408

30. Pour AB, Park Y, Park TS, Hong JK, Hashim M, Woo J, Ayoobi I (2018) Evaluation of ICA and CEM algorithms with Landsat-8/ ASTER data for geological mapping in inaccessible regions. Geocarto Int 34(7):785-816

31. Pour AB, Park Y, Park TS, Hong JK, Hashim M, Woo J, Ayoobi I (2018) Regional geology mapping using satellite-based remote sensing approach in Northern Victoria Land, Antarctica. Polar Sci 16:23-46

32. Pour AB, Park TS, Park Y, Hong JK, Zoheir B, Pradhan B, Ayoobi I, Hashim M (2018) Application of multi-sensor satellite data for exploration of $\mathrm{Zn}-\mathrm{Pb}$ sulfide mineralization in the Franklinian Basin, North Greenland. Remote Sens 10:1186. https://doi. org/10.3390/rs10081186

33. Pour AB, Hashim M, Park Y, Hong JK (2018) Mapping alteration mineral zones and lithological units in Antarctic regions using spectral bands of ASTER remote sensing data. Geocarto Int 33(12):1281-1306

34. Rajendran S (ed) (2009) Hyperspectral remote sensing and spectral signature applications. New Indian Publishing agency, New Delhi, p 546

35. Ramakrishnan D, Bharti R, Singh KD, Nithya M (2013) Thermal inertia mapping and its application in mineral exploration: results from Mamandur polymetal prospect, India. J Earth Syst Sci 122(1):93-106

36. Ramakrishnan D, Kusuma KN (2008) Marine clays and its impact on the rapid urbanization developments: a case study of Mumbai area using EO-1-Hyperion data. In: Rajendran S (ed) Hyperspectral remote sensing and spectral signature applications. New India Publishing Agency, New Delhi

37. Rossman GR (1988a) Optical spectroscopy. In: Hawthorne FC (ed) Spectroscopic methods in mineralogy and geology. Reviews in mineralogy, vol 18 . Minerological Society of America, Washington DC, pp 207-254

38. Rossman GR (1988b) Vibrational spectroscopy of hydrous components. In: Hawthorne FC (ed) Spectroscopic methods in mineralogy. Reviews in mineralogy, vol 18. Minerological Society of America, Washington DC, pp 193-206

39. Sabins FF (1999) Remote sensing for mineral exploration. Ore Geol Rev 14:157-183

40. Sinha-Roy S, Malhotra G, Mohanty M (1998) Geology of Rajasthan. Geological Society of India, Bangalore

41. Sanjeevi S, Abhishekh PV (2006) Spectral unmixing of hyperspectral data to map bauxite deposits. In: Proceedings of international society for optics and photonics, vol 6405, pp 64051N

42. Sanjeevi S (2008) Targeting limestone and bauxite deposits in southern India by spectral unmixing of hyperspectral image data. Int Arch Photogramm Remote Sens Spat Inf Sci 37(B8):1189-1194

43. Sheikhrahimi A, Pour BA, Pradhan B, Zoheir B (2019) Mapping hydrothermal alteration zones and lineaments associated with orogenic gold mineralization using ASTER remote sensing data: a case study from the Sanandaj-Sirjan Zone, Iran. Adv Space Res 63:3315-3332

44. Sun L, Khan S, Shabestari P (2019) Integrated hyperspectral and geochemical study of sediment-hosted disseminated gold at the goldstrike district, Utah. Remote Sens 11:1987. https://doi. org/10.3390/rs11171987

45. Sun Y, Seccombe PK, Yang K (2001) Application of IR spectroscopy to define alteration zones associated with Elura zinc-leadsilver deposit NSW Australia. J Geochem Explor 73:11-26

46. Sharma UR, Chattoraj SL, Khatun M, Champati ray PK (2014) Mineralogical mapping using field and image based spectra in parts of Delhi-Aravalli Fold-Belt, Rajasthan. In: Pre conference volume of the Indian Geological Congress, Itanagar (Extended abstract) volume, Nov. 27-29, pp 107-108

47. Sharma S (2014) Rajasthan government to allow more mining activities, open tribal areas, Times of India. Online Dec 13. http:// timesofindia.indiatimes.com/india/Rajasthan-government -to-allow-more-mining-activities-open-tribal-areas/articlesho w/45499860.cms. Accessed 22 May 2016

48. Thompson AJB, Hauff PL, Robitaille A (1999) Alteration mapping in exploration: application of short-wave infrared (SWIR) spectroscopy. Soc Econ Geol Newsl 39:16-27

49. Trude KVV, Clark RN (1989) Spectral characteristics of chlorites and $\mathrm{Mg}$-serpentines using high-resolution reflectance spectroscopy. J Geophys Res 94(B10):13997-14008

50. Van der Meer F, de Jong $S$ (eds) (2001) Imaging spectrometry: basic principles and prospective applications. Springer, Berlin

51. van der Meer FD, van der Werff HMA, van Ruitenbeek FJA, Hecker CA, Bakker WH, Noomen MF, van der Meijde M, Carranza EJM, de Smeth JB, Woldai T (2012) Multi-and hyperspectral geologic remote sensing: a review. Int J Appl Earth Obs Geoinf 14:112-128

52. van der Meer FD (1999) Imaging spectrometry for geological remote sensing. Neth J Geosci 77(2):137-151

53. van der Meer FD (2012) Remote sensing image analysis and geostatistics. Int J Remote Sens 33:5644-5676

54. Yang K, Lian C, Huntington JF, Peng Q, Wang Q (2005) Infrared spectral reflectance characterization of the hydrothermal alteration at the Tuwu Cu-Au deposit Xinjiang, China. Miner Depos 40:324-336

55. Zoheir B, Emam A, Abdel-Wahed M, Soliman N (2019) Multispectral and radar data for the setting of gold mineralization in the south eastern desert, Egypt. Remote Sens 11:1450. https://doi. org/10.3390/rs11121450

56. Zoheir B, El-Wahed MA, Pour AB, Abdelnasser A (2019) Orogenic gold in transpression and transtension zones: field and remote sensing studies of the Barramiya-Mueilha sector Egypt. Remote Sens 11:2122. https://doi.org/10.3390/rs11182122

Publisher's Note Springer Nature remains neutral with regard to jurisdictional claims in published maps and institutional affiliations. 